\title{
Orbitofrontal cholesterol granuloma: case report and review of the literature
}

\author{
Lorenzo Ugga ${ }^{1}$, Salvatore Stilo ${ }^{1}$, Pasquale Napolitano ${ }^{2}$, Elia Guadagno ${ }^{3}$, Adriana Iuliano ${ }^{2}$, Maria Laura del \\ Basso de Caro ${ }^{3}$, Andrea Elefante ${ }^{1}$ \\ ${ }^{1}$ Department of Advanced Biomedical Sciences, Neuroradiology Unit, ${ }^{2}$ Department of Neurosciences, Reproductive Sciences and \\ Odontostomatology, ${ }^{3}$ Department of Advanced Biomedical Sciences, "Federico II” University, Naples, Italy
}

Correspondence to: Lorenzo Ugga, MD. Department of Advanced Biomedical Sciences, Neuroradiology Unit, University "Federico II" Via Pansini, 5 , 80131, Naples, Italy. Email: lorenzo.ugga@gmail.com.

Submitted Feb 27, 2017. Accepted for publication Mar 14, 2017.

doi: 10.21037/qims.2017.04.04

View this article at: http://dx.doi.org/10.21037/qims.2017.04.04

\section{Introduction}

Cholesterol granuloma of the orbit is an uncommon condition. It affects almost exclusively the frontal bone in the supero-temporal quadrant of the orbit. It is an osteolytic lesion well-circumscribed by a fibrous capsule, with a granulomatous reaction surrounding cholesterol crystals and old hemorrhage. We report the case of a patient whose clinical and radiological findings were sufficient to make a correct diagnosis.

\section{Case report}

A 73-year-old man came to the Orbital Pathology Department of our Institute following an access to the emergency room for a sudden drop in sight and difficulties when walking. The patient reported a history of a proptosis for the past 2 years, during which he has not sought medical treatment. Furthermore, he reported a head injury occurred several years earlier.

On physical examination, an inferior displacement of the right eye was detected (Figure 1), with limitation of visual field in all directions; visual acuity was normal. The examination of the fundus showed synchysis scintillans in the right eye; the optical disc presented sharp margins with an increase of physiological excavation in the right eye; there was also an alteration of the retinal pigment epithelium on the posterior pole.

Computed tomography (CT) scan (Figure 2) revealed an ovoid, smoothly edged lesion of about $3 \mathrm{~cm}$ in the superior aspect of the right orbit, with a large bony defect of the floor of frontal sinus through which the lesion extended into the sinus. Due to these findings, the patient underwent contrast-enhanced magnetic resonance imaging (MRI) scan of the brain and orbits at 3 Tesla (Trio, Siemens, Erlangen, Germany).

The MR scan (Figure 3) confirmed the lesion in the superior aspect of the right orbit, displacing inferiorly the periorbita, the levator palpebrae superioris and the superior rectus muscles, and compressing the optic nerve. It showed high signal on both T1-weighted and T2weighted images, which is unchanged after fat suppression, suggestive of chronic hemorrhage. On T2-weighted, the lesion was surrounded by a hemosiderin rim. The lesion did not enhance after contrast agent administration. These findings suggested a diagnosis of cholesterol granuloma. The MR examination also showed encephalomalacia of the orbital surfaces of the frontal lobes, due to previous cerebral contusion.

Subsequently the patient underwent biopsy of the lesion which highlighted the presence of "chronic granulomatous inflammation organized around keratin strips, hemosiderin pigment deposits, red cell extravasation and calcifications", typical findings of cholesterol granuloma (Figure 4). The patient underwent surgery for resection with anterior orbitotomy through subbrow incision. Macroscopically it was possible to see an erosion of the posterior third of orbital roof due to the presence of an intraosseous expansile lesion (Figure 5). The capsule had invaded the orbital cavity 


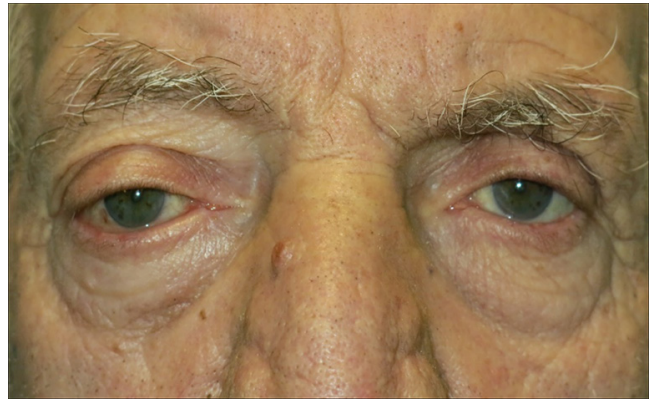

Figure 1 Physical examination: inferior dislocation of the right globe.
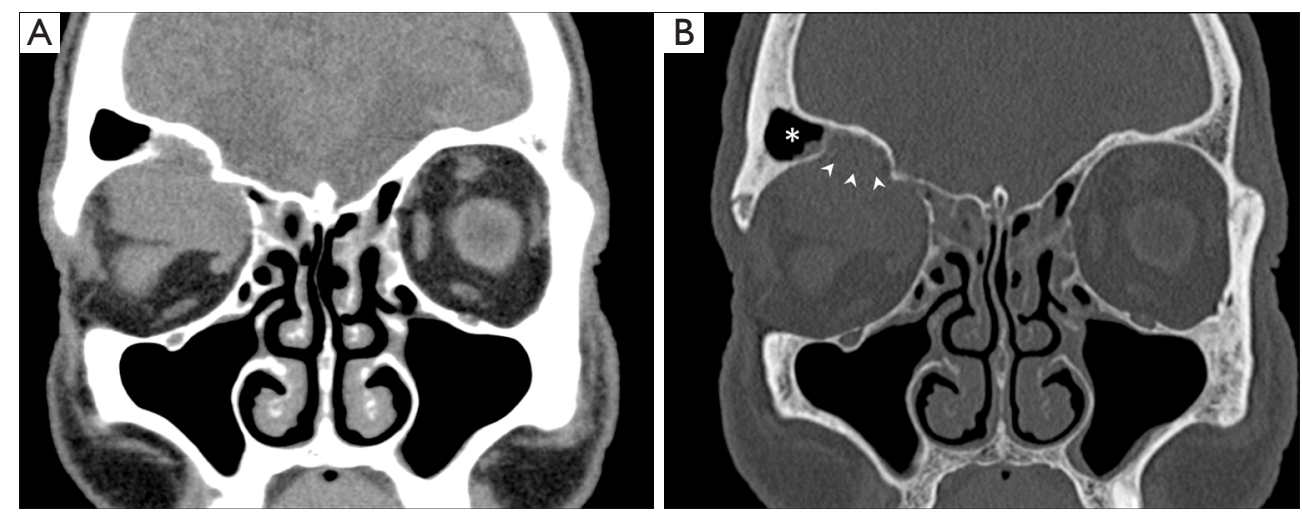

Figure 2 CT scan coronal reformatted images with soft tissue (A) and bone (B) algorithm reconstructions. Arrowheads: erosion of the frontal sinus floor; asterisk: frontal sinus. CT, computed tomography.
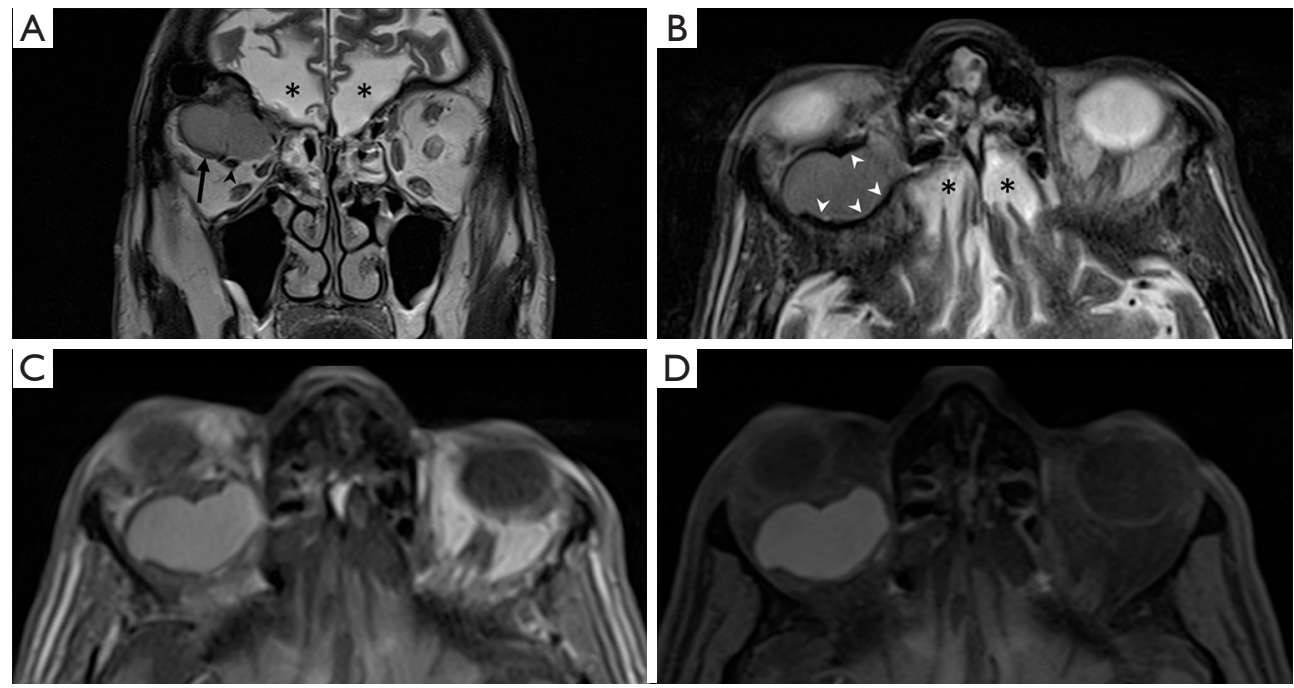

Figure 3 Coronal turbo spin echo T2-weighted (A), axial turbo spin echo T2-weighted (B), axial turbo spin echo T1-weighted (C) and axial turbo spin echo T1-weighted with fat suppression (D) MR images. Asterisks: encephalomalacia of the orbital surfaces of the frontal lobes, due to previous cerebral contusion; black arrowhead: optic nerve; black arrow: levator palpebrae superioris and superior rectus muscles; white arrowheads: hemosiderin rim of the lesion. 


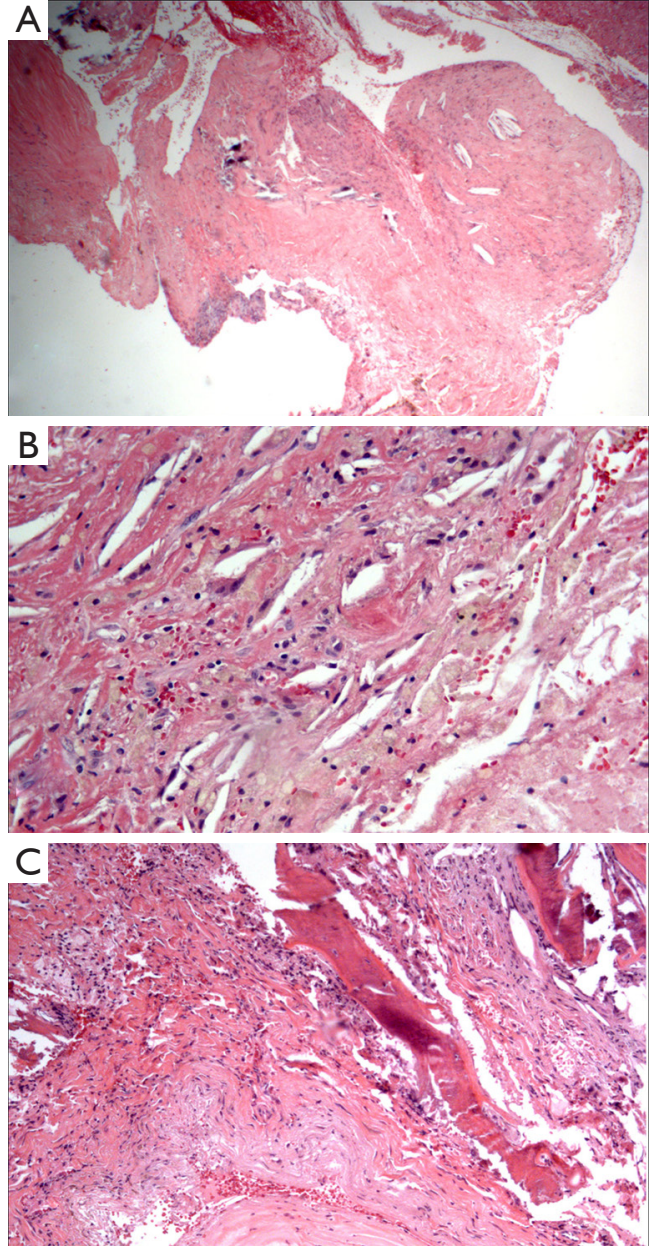

Figure 4 Histologic examination, hematoxylin and eosin stain (A: 5x, B: 20x, C: 10x). Microscopic examination revealed fibrotic tissue (A) affected by chronic inflammation with granulomatous reaction (B) and erithrocyte extravasation. A lamella of bone tissue was present $(\mathrm{C})$.

possible to point out old hemorrhage in the injured context. There is a male prevalence, especially in young or middleaged man (1). This kind of lesion is described in various bony structures of the head such as zygoma (1), maxilla (2) and mandible (3), although in neurosurgical practice it is most frequently found in the petrous temporal bone.

Although it is rare, cholesterol granuloma can develop in the context of frontal bone diploe with possibility of invasion of extraperiosteal space in circumstances of a larger lesion (4-6).

This may result in sensation of fullness of the orbital cavity with inferior displacement of globe with painless proptosis and diplopia. Involvement of anterior cranial fossa

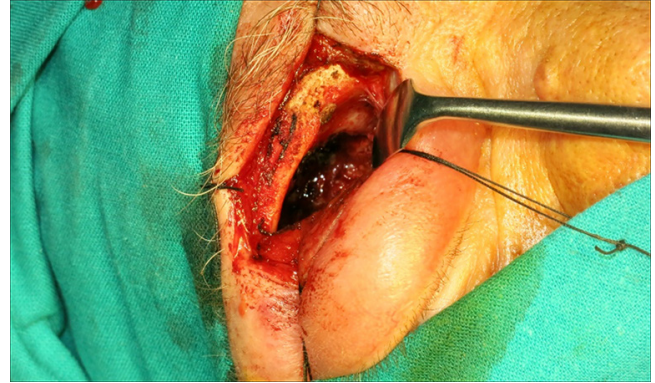

Figure 5 Exposure of the lesion with an anterior orbitotomy approach. Incision below the eyebrow, exposure of the frontal margin of the orbit and gap by Sewall spatula with visualization of the granuloma.

is uncommon (1).

The first case of orbital cholesterol granuloma was reported by Denig in 1902 (7). Successively, several additional studies have been done on the subject. Most of these highlights of imaging features of these lesions can be pathognomonic. Consequently, it is possible to establish the diagnosis based on imaging such as CT and MRI.

CT images show a round mass generally in the superotemporal region of the orbit (even if in our case the mass was located in the superomedial) with regular borders and isodense to brain tissue, rarely hypodense. It appears as a non-calcified mass without sclerotic margins with bone spicules in its context (8). These findings are associated with bone erosion that leads to extra-periosteal extension in the extra-conal space resulting in proptosis as well as inferior displacement of the ocular globe. The mass does not show post-contrast enhancement (4).

Various studies have approached this type of pathology in defining the outstanding characteristics on MRI such as those conducted by Khalatbari (9), Chow (4), Aferzon (10) and Ochiai (11). Some of these studies have demonstrated characteristics of the lesion in MRI which are increasingly overlapping. The studies showed lesions with scattered area of high signal areas in both T1-weighted and T2-weighted images between the septa or foci of low signal in MRI due to chronic hemorrhage. The radiological appearance is supported by the histopathological findings of chronic hemorrhage products and fibrous tissue, in addition to the inflammatory infiltrate.

Gadolinium administration does not contribute in characterization of these lesions due to non-enhancement (4).

As to our knowledge, there is only one case that was reported with discordant features to these studies as well 
as to our case; showing moderate signal intensity on T1weighted images and high signal intensity on T2-weighted images (12).

An orbitotomy with anterior access (sometimes a lateral one) with drainage and removal of the pathologic tissue is the definitive treatment of cholesterol granuloma. To prevent recurrence a thorough curettage of the orbital cavity is essential due to the adherence of granulomatous material to the bone (6).

The main differential diagnoses are dermoid or epidermoid cysts, lacrimal gland tumors and cholesteatoma. The differential diagnosis between epidermoid and dermoid cysts and cholesterol granuloma is not simple, neither clinically nor on CT images. Epidermoid and dermoid cysts usually appear as anterosuperior extraconal masses with lipid, fluid, or mixed contents. On CT they may contain areas of fat attenuation with a bony defect within the lateral orbital wall. They have sclerotic margins without destructive changes. On MRI, fat components show low signal on fat-saturated sequences; moreover, epidermoid cysts may show diffusion restriction (13-17). Lacrimal gland tumours on CT may appear hyperdense to the brain, containing calcification, showing irregular bone destruction with or without sclerosis and enhancing with intravenous contrast. Moreover, they are usually associated with severe pain (4). It may be difficult to differentiate a cholesteatoma from a cholesterol granuloma. They are relatively rare orbital lesions that may involve the superior portion of the orbit and present with similar symptomatology (proptosis, globe ptosis and double vision developing over weeks to years) and histopathological features. However, there is a key feature that allows the differentiation: the cholesterol granuloma does not have an epithelial lining. It is crucial to distinguish these two lesions in view of difference in recurrence rate. In fact, the cholesteatoma may recur with possibility of malignancy found at the time of re-exploration (18).

\section{Conclusions}

Cholesterol granuloma of the orbit is a rare disease. However, although uncommon, these lesions should be identified by the radiologist due to the peculiar features, especially of MRI. The radiologist should be aware of this rare site of the cholesterol granuloma and take this into consideration to arrive to the differential diagnosis. The integration of clinical examination with imaging techniques is generally sufficient for a correct preoperative diagnosis.

\section{Acknowledgements}

None.

\section{Footnote}

Conflicts of Interest: The authors have no conflicts of interest to declare.

Informed Consent: Written informed consent was obtained from the patient for publication of this case report and any accompanying images.

\section{References}

1. McNab AA, Wright JE. Orbitofrontal cholesterol granuloma. Ophthalmology 1990;97:28-32.

2. Graham J, Michaels L. Cholesterol granuloma of the maxillary antrum. Clin Otolaryngol Allied Sci 1978;3:155-60.

3. Hirshberg A, Dayan D, Buchner A, Freedman A. Cholesterol granuloma of the jaws. Report of a case. Int J Oral Maxillofac Surg 1988;17:230-1.

4. Chow LP, McNab AA. Orbitofrontal cholesterol granuloma. J Clin Neurosci 2005;12:206-9.

5. Parke DW 2nd, Font RL, Boniuk M, McCrary JA 3rd. 'Cholesteatoma' of the orbit. Arch Ophthalmol 1982;100:612-6.

6. Loeffler KU, Kommerell G. Cholesterol granuloma of the orbit-pathogenesis and surgical management. Int Ophthalmol 1997;21:93-8.

7. Denig R. Subperiosteal blood cyst of the orbit; report of a case. Ophthalmic Record 1902;11:187.

8. Dobben GD, Philip B, Mafee MF, Choi K, Belmont H, Dorodi S. Orbital subperiosteal hematoma, cholesterol granuloma, and infection. Evaluation with MR imaging and CT. Radiol Clin North Am 1998;36:1185-200.

9. Khalatbari MR, Moharamzad Y. Recurrent orbitofrontal cholesterol granuloma in pediatric patient: case report and review of the literature. Childs Nerv Syst 2012;28:291-6.

10. Aferzon M, Millman B, O'Donnell TR, Gilroy PA. Cholesterol granuloma of the frontal bone. Otolaryngol Head Neck Surg 2002;127:578-81.

11. Ochiai H, Yamakawa Y, Fukushima T, Nakano S, Wakisaka S. Large cholesterol granuloma arising from the frontal sinus-case report. Neurol Med Chir (Tokyo) 2001;41:283-7. 
12. Dickey JB, Mullenix CD, O’Grady RB. Atypical magnetic resonance findings in an orbitofrontal cholesterol granuloma. Ophthal Plast Reconstr Surg 1992;8:215-20.

13. Caranci F, Tedeschi E, Leone G, Reginelli A, Gatta G, Pinto A, Squillaci E, Briganti F, Brunese L. Errors in neuroradiology. Radiol Med 2015;120:795-801.

14. Hill CA, Moseley IF. Imaging of orbitofrontal cholesterol granuloma. Clin Radiol 1992;46:237-42.

15. Tortora F, Cirillo M, Ferrara M, Belfiore MP, Carella C, Caranci F, Cirillo S. Disease activity in Graves' ophthalmopathy: diagnosis with orbital MR imaging and correlation with clinical score. Neuroradiol J 2013;26:555-64.

16. Tortora F, Prudente M, Cirillo M, Elefante A, Belfiore MP,
Romano F, Cappabianca S, Carella C, Cirillo S. Diagnostic accuracy of short-time inversion recovery sequence in Graves' Ophthalmopathy before and after prednisone treatment. Neuroradiology 2014;56:353-61.

17. Strianese D, Piscopo R, Elefante A, Napoli M, Comune C, Baronissi I, Liuzzi R, Ferrara M, D'alessandro A, Ruggiero P, Napolitano P, Grassi P, Iuliano A, Russo C, Brunetti A, Bonavolontà $\mathrm{G}$. Unilateral proptosis in thyroid eye disease with subsequent contralateral involvement: retrospective follow-up study. BMC Ophthalmol 2013;13:21.

18. Jordan DR, Spitellie P, Brownstein S, Rawlings N, Gilberg SM. Orbital cholesterol granuloma and cholesteatoma: significance of differentiating the two. Ophthal Plast Reconstr Surg 2007;23:415-7.
Cite this article as: Ugga L, Stilo S, Napolitano P, Guadagno E, Iuliano A, del Basso de Caro ML, Elefante A. Orbitofrontal cholesterol granuloma: case report and review of the literature. Quant Imaging Med Surg 2017;7(3):373-377. doi: 10.21037/ qims.2017.04.04 